Max-Planck-Institut für demografische Forschung

Max Planck Institute for Demographic Research

Konrad-Zuse-Strasse 1 - D-18057 Rostock · GERMANY

Tel +49 (0) 3812081 - 0; Fax +49 (0) 3812081 - 202;

http://www.demogr.mpg.de

MPIDR WORKING PAPER WP 2005-015

MAY 2005

\title{
Mapping Social Influence on Fertility: a Mix-Method Approach to Data Collection
}

Laura Bernardi (bernardi@demogr.mpg.de)

Holger von der Lippe (vdlippe@ demogr.mpg.de)

Sylvia Keim (keim@demogr.mpg.de)

(C) Copyright is held by the authors.

Working papers of the Max Planck Institute for Demographic Research receive only limited review. Views or opinions expressed in working papers are attributable to the authors and do not necessarily reflect those of the Institute. 


\title{
Mapping Social Influence on Fertility: a Mix-Method Approach to Data Collection
}

\author{
Laura Bernardi, Holger von der Lippe, Sylvia Keim \\ Max Planck Institute for Demographic Research \\ Presented at the PAA Annual Meeting 2005, Philadelphia, March 31-April 2- Session 111
}

\begin{abstract}
Keywords: social networks, family formation, fertility decision-making, peers, social influence, qualitative approach

Theoretical propositions on the importance of social effects arising from informal interaction on fertility change are not yet supported by systematic empirical evidence (Kohler et al. 2002). The correct identification of informal relationships salilent for fertility decisionmaking and the comparability of social networks across population subgroups present major problems. This paper illustrates the design of a research project that specifically addresses these two problems. The project investigates the role of informal social networks on fertility decisions in East and West Germany by employing a multi-method research strategy. We use a combination of in-depth interviews, network charts, and network grids to elicit a map of individual personal relationships and to analyze their influence on respondents' fertility decisions and intentions. We collect information in parallel from the respondents and from up to three members of their social network.
\end{abstract}

\section{Introduction}

The life course of otherwise similar individuals may differ because the social environment they are embedded in differs. As the social environment varies, so do the practices, norms, and values about the time and forms in which life events occur or should occur as well as how they are sequenced or expected to be. These norms and practices are grounded in the cumulative consciousness and experience of the society and experienced by the individual through the concrete networks of people (s)he is in contact with.

Some of the most significant events marking a turning point in the life course of young men and women are related to the development of family formation. The birth of the first child brings in its wake a reallocation of time and resources, the re-organization of daily activities and time use, temporary or definitive changes as to participation in the labor force, role and identity redefinition as adults, as parents, as couple, and, finally, changes in the relationships with relatives and friends. All of these changes are likely to be considered by potential parents, who may have tasted them from the experience of others.

The relationship between the individual's social environment and his or her decision-making as to childbearing can be studied from two different perspectives: One can focus on how the 
social environment changes as a consequence of parental behavior or, alternatively, on how social relationships affect childbearing choices. The first perspective mainly looks at the effect of having or not children on the social environment of parents, like changes in the social network composition as a consequence of the birth of the first child or according to the age of the youngest child. The second perspective concentrates on the opposite causal relationship, which is the influence of the social environment on individual or couple childbearing decision-making. Our research takes the second perspective, though we are aware that this distinction is a useful analytic tool and does not necessarily mirror the real processes, given that the actual causal relationship is likely to be a complex one implying recursiveness ${ }^{1}$. We are interested in the question of how the characteristics of social interaction in informal social networks of kin and peers influence childbearing expectations, attitudes, preferences, and ultimately behavior in different social contexts. We do not answer questions on the mechanisms regulating a change in (or the stability of) social networks as such as a consequence of childbearing choices. In Section 2, we outline the way in which social interaction is gaining relevance in demographic explanations of fertility behavior. There follows a definition of our research design in Section 3. The next presents our analyzing strategy, and in Section 5, we illustrate the potential of this strategy by means of some selected examples from preliminary analyses.

\section{The social network and fertility: background}

\subsection{Social networks and fertility change}

Recent years have witnessed an increasing inclusion of social interaction effects in demographic accounts on fertility change (Behrman at al. 2002). The recognition that individuals and couples are socialized actors embedded in a web of informal relationships with kin relatives and peers led researchers to include social mechanisms, like social learning and social influence, in their models (Bongaarts and Watkins 1996). Despite the fact that fertility choice belongs to the sphere of private decision-making, individual fertility preferences may be shaped by social interaction in that individuals engage in a reciprocal exchange of information about the consequences of specific childbearing choices. They may question their evaluations on this matter by learning about the experiences and preferences of others, become aware of social norms and expectations about family-related behavior, and may adjust their feelings on the desirability of alternative choices. If these models are true, it

1 A discussion on 'thin behavior' held in Chattoe (2003) is relevant to this point. 
would mean that there is some interdependence in individual fertility preferences and behavior due to the social interaction among relatively small groups of individuals. This interdependence produces social effects observable in macro patterns, for instance by affecting the pace of fertility change in the population. The main idea is that social interaction can accelerate or decelerate the rhythm of changes in fertility behavior. These changes may have been initiated as a response to changes within the socioeconomic or institutional framework of incentives, but their effect is multiplied by the social mechanisms of learning and influence (Kohler et al. 2002).

The first models of fertility change incorporated social interaction only at the aggregate level (Montgomery and Casterline 1993, Rosero-Bixby and Casterline 1994). In these models social interaction effects accounted for observed patterns of behavioral diffusion like the diffusion of family size in England and Wales (Bocquet-Appel and Jacobi 1998) ${ }^{2}$. The main idea of these models was that innovative fertility preferences diffuse within a population through the patterns of social interaction (Rogers and Kincaid 1981, Retherford and Palmore 1983, Knodel et al. 1984). Typically, in these models a diffusion process travels through institutional and informal channels of communication and its dynamics are subject to acceleration and deceleration, as in an epidemiological contagion model. This leads to the possibility of very rapid and persistent changes in fertility behavior, at a pace that may be unrelated to the pace of socioeconomic or institutional policy changes (Kohler et al. 2002). The power of informal relationships in influencing individual childbearing behavior is also dependent on the structure and intensity of social interaction (Kohler 2000) ${ }^{3}$. Models including these kinds of social effects are called into cause in the explanation of the spatial dynamics of the first fertility transition ${ }^{4}$ in XIXth century Europe and in XXth century African and Asian developing countries (Knodel and van de Walle 1979, Watkins 1987, Cleland and Wilson 1987, Pollak and Watkins 1993, Palloni 1998).

However, the indirect nature of the evidence of social influence mechanisms provided by aggregate data is unsatisfactory for at least two reasons. First, time and geographical patterns of diffusion constitute empirical evidence of social effects, but the social mechanisms that cause them cannot be specified by looking only at the outcome (McNicoll 1992, Strang and Soule 1998, Manski 2000). The micro-foundation of diffusion models rests on the social

\footnotetext{
${ }^{2}$ See the first chapter in Bernardi (2002) for a review

3 Kohler (2000) illustrates this point by way of analysis in that he developed a dynamic model where social interaction mechanisms lead to multiple stable equilibria, corresponding to different demographic regimes, and characterized by a specific fertility rate and tempo. This exercise shows that individual and population fertility are interdependent and, more importantly, that the total effect of the interaction depends on the configuration of social interaction within the population.

4 The expression 'first fertility transition' refers to the process by which fertility levels decline to population replacement levels.
} 
mechanisms working at the individual level, like social learning and social influence. The interdependence of individual preferences and behavior needs to be justified by an appropriate theory of action, whereas the inclusion of social interaction in the demographic theoretical framework is based on relatively simplistic hypotheses on the social mechanisms (Chattoe 2003, Montgomery and Casterline 1996:159). Secondly, any test of social network effects is incomplete if it cannot reconstruct "who is connected to whom", that is the structure of the channels through which social mechanisms act. These two aspects still require thorough empirical investigation in order to define how social influence affects fertility choice. Despite its growing prominence within the explanatory frameworks of demographic transition, the empirical assessment of the social mechanisms through which diffusion works proves to be challenging. While there is substantial effort in modeling the role that social interaction plays in the dynamics of fertility preferences, there is little empirical evidence on the social mechanisms at work and on the variation in the composition of the networks of informal relationships in relation to fertility behavior. In the next section, we provide an overview of some of these studies.

\subsection{Social networks and fertility intentions and behavior}

The need for direct evidence of social mechanisms and of testable propositions on the effect of ties and network characteristics on fertility behavior points to the collection of individual level data on social networks both by means of representative surveys and ethnographic or qualitative studies. Examples of research studying in-depth the role of kin members in determining the patterns of union formation are more common in the social demographic literature dealing with non-European populations as opposed to European populations. However, there are a few examples of empirical research on social networks directed at explaining current family and fertility changes in Europe (Nazio and Blossfeld 2003, Rosina and Di Giulio 2003). A few qualitative studies register the existence of normative pressure on childbearing decisions by relevant others, but they neither focus on the different ways in which influence is conveyed nor on the impact of network characteristics (Busfield and Paddon 1977, Campbell 1985, McAllister and Clarke 1998, Gerson 1985). In-depth interviews with Italian women on the social context of reproductive decisions highlight the importance of non-cognitive grounds for social effects, like emotions and affective factors circulating in social interaction. The consequence of cognitive and non-cognitive mechanisms is a plausible synchronization effect of childbearing events in close-knit groups of friends, a sort of social clock that starts ticking when childbearing events become visible and close by vicarious experience in the social network (Bernardi 2002). Social mechanisms of influence can be more or less hindered, depending on their interaction with local dominant family 
values that regulate the occasions and the forms of acceptable social interaction (Bernardi 2004).

Social networks are not only influential as a channel for the circulation, creation, and enforcement of beliefs, meanings, attitudes, norms, and preferences, analyses on egocentered social networks currently available and based on large surveys stress a complementary interpretation of the role of social interaction in informal networks, based on the sociological literature on social capital. In this perspective, social networks are mainly pools of additional resources available to the individual (Lin 1999). Social relationships understood as social capital may affect childbearing decision-making in two ways: they a) constitute a pool of resources available to the individual or b) are in themselves the resources that individuals hope to gain through parenthood.

The first scenario is rather straightforward, though most research focuses on social support as a resource ex post, when potentially stressful demographic events occurred, like adolescence, single motherhood (Amato 1991, Tietjen 1985), or divorce (Leslie and Gradly 1985). Some recent empirical evidence from countries under considerable economic uncertainty where social capital is particularly important show that the number of supportive relationships (parents, friends, and colleagues) and the intention to have a second child are highly correlated (Bühler and Fractak 2004).

The second scenario is that childbearing is one form of parents' investment, yielding expected returns in social capital. In this perspective, the positive association between the intention to have a child and the expectations that this would lead to a closer relationship with parents and partners, as observed in Bulgaria, would mean that the transition to parenthood is triggered by individual expectations to increase the number of supportive relationships through offspring (Bühler 2004).

Our necessarily brief review of studies on the relationship between individual social networks and fertility choices suggests that the link between the theoretical arguments on the relevance of social networks to fertility decisions and the empirical implementation of research designs is still an open challenge. Little is known about the conditions under which the mechanisms of social influence are more or less likely to work and how their efficacy or prominence varies according to variations in the characteristics of individual ties, network configurations, and specific cultural and societal environments.

In the following sections, we describe an on-going research, which is designed to meet some of these challenges. The focus of the paper is on the methodological and sampling approach. The investigation addresses the question of how family formation and parenthood are 
embedded in social interactions occurring within a young adult's network of friends, peers, and family in East and West Germany. This study takes a qualitative focus via subjectcentered interviews with Egos and some of their Alters, but it also collects standardized information concerning specific characteristics of the ego-centered networks and their members. The study has three aims. First, we aim at capturing the young adults' subjective framework of meanings and relevance in East and West Germany concerning family formation (that is, the birth of a first child) and family extension (in our case, the birth of a second child). Second, we want to understand which social mechanisms that affect fertility behavior are present in informal networks and how they work. Finally, we want to assess in what ways differences in social network composition and in social context conditions vary the effectiveness of the social mechanisms themselves.

\section{The social network and fertility: the research design}

\subsection{Project location}

In order to explore social interactions in different social contexts, we have chosen to place our study in two different urban settings, the cities of Rostock in East Germany and Lübeck in West Germany, emulating in part the logics of a social 'natural experiment'. The two cities are located at the opposite sides of the former border of East and West Germany's former border, and are only $100 \mathrm{~km}$ apart. On the one hand they share many common features, on the other they belong to what has been designated as two different fertility "regimes".

As to the similarities between the two cities, they have a comparable historical and societal background, e.g., until the postwar period they were largely comparable "Hanseatic twins". Today, they are largely similar concerning their population size (classed as medium cities in Germany, with about 200.000 vs. 215.000 inhabitants), their socio-economic situation (economic strains, with unemployment being a little higher in Rostock: $18 \%$ vs. 13\%) and age structure (demographically, Lübeck is an "old" city, while Rostock is an "aging" one due to the out-migration of younger cohorts and a sharp fertility decline after reunification). The differences between East and West Germany before unification in 1990 in the timing of fertility, the typologies of families, and gender relations have been amply researched. In this paper, and drawing heavily on Kreyenfeld (2002), we just sketch the main features of the differences in fertility patterns, referring to two of the most important and usual indicators: age at first birth and the percentage of definitive childlessness. Comparing the behavior of the same cohorts in East and West Germany, women born in 1940 and living in East Germany had their first child on average at 22 versus 24.2 for their western counterparts. This 
difference of two years constantly increased and reached up to 4 years for the cohorts born in 1958. The level of childlessness diverged substantially as well, starting from the same level, $12 \%$, for the cohort norm in 1940. In East Germany, 8\% of the women born in 1958 stayed childless, while in the West the level of definitive childlessness reached the very high level of $23 \%$. Another remarkable difference related to family formation is the high share of employed women in the former GDR. In 1989, women's employment rate ${ }^{5}$ in the GDR was $82 \%$ compared to only 56\% in the FRG (Hülser 1996: 47 f). Additionally, part-time work was more common in the $\mathrm{FRG}^{6}$, with $32 \%$ of the employed women working part-time (whereof the majority worked less than 25 hours a week) compared to $27 \%$ in the GDR (whereof the majority worked more than 25 hours a week) (Hülser 1996: 51). While in the GDR, it was common for mothers to work full-time, the male breadwinner model prevailed in the FRG. This brief outline reveals how different the family formation experience has been for the parents of those who are in fertility ages today, and these latter are the basis of our sample.

\subsection{A purposive sampling strategy}

Our purposive sample strategy targets individuals belonging to the cohorts who left secondary school in 1994; they are aged between 26 and 31 in 2004 (which is an age range in which on average first and second births among women occur). The choice of these cohorts means that we have interviewees for whom family formation and parenthood is likely to be a salient topic and who may have experienced directly parenthood or vicarious parenthood in their social circle. In order to control for influences coming from early socialization during adolescence, we recruit respondents who experienced the same schooling in each of the two settings. Half of the sample (32) graduated from the same German 'Gymnasium' - higher level secondary education institution - and the other half from the same 'Realschule' - an institution of middlelevel secondary education - and attended the same school class. It is among men and women with high and medium educational levels that fertility behavior has changed considerably in Germany in recent years (Kreyenfeld 2001).

In addition to the 64 main interviews, we directly collect information from up to three relatives and peers. In each setting, our interviewees are divided into two groups: main respondents (from now on Ego) and the members of his or her social networks (from now on Alters). Interviews with Alters are generally conducted with one of Ego's parents, the current

\footnotetext{
${ }^{5}$ The rate of female employees as to all women aged 15-60 (GDR) or 15-65 (FRG).

${ }^{6}$ Also, the definition of part-time work differed in the two German states. In the GDR, any working time less than 40 hours was considered part-time work. In the FRG, however, part time work had to be less than 36 hours by definition.
} 
partner, and a close friend when available. The school class approach to a certain extent facilitates the recruitment of both egos and alters since potential interviewees are more likely to accept interview if someone else they know has participated in it already. If potential interviewees no longer live in the city where they obtained their secondary studies diploma, we interview them at their current place of residence. We are aware of the possibility that those who are far from Rostock or Lübeck since long are also those who are less likely to be found because the chain of contacts is more likely to have broken with distance. Figure 1 shows the sample design and Table 1 presents the sample achieved as late as March 2005.

[Figures 1 and Table 1 about here]

\subsection{Mix-method data collection}

The nuts and bolts of our data collection consist of three parts: a) a problem-centered interview guideline, b) a network chart and a network grid integrated in the interview guidelines, c) a short socio-demographic questionnaire submitted at the end of the interview.

\subsubsection{The interview guideline}

Our problem-centered interview (PCI, Witzel 1985, 2000) ${ }^{7}$ is designed to combine in one instrument two objectives: methodical openness to capture the meanings and subjective framework of references and a specific focus on childbearing decisions and social interaction. In order to achieve openness at the start of the interview, we begin with a non-directive input that asks the respondents to provide a narration on their life after school without any further specifications of which life domains to focus on. Education histories, employment histories, past and current partnerships, family of origin, family formation, and relationships with peers colleted in the first part of the interview reflect the respondents' subjective frame of relevance. This openness provides us with the opportunity to appreciate how meanings, motives, and desires concerning family formation are embedded in the context of respondents' life-course (Flick et al. 2000:14). ${ }^{8}$

In order to achieve the second objective, that is to focus on central topics in the interview, we direct the interview toward questions based on the theoretical assumptions of fertility decisions, social interaction, and social influence. The PCI method explicitly requires the use

\footnotetext{
${ }^{7}$ The PCI is based on the tradition of Grounded Theory (Glaser \& Strauss, 1998) as an elaborate method for combining deductive and inductive elements in a flexible interplay (Mey 1999: 145; Keim 2004; von der Lippe, 2004: 104). 8 This also means that the respondents need to have the possibility to state that certain topics are irrelevant for them and why so.
} 
of an interview guideline. Our guideline consists of seven blocks of questions (see box A).

The sequence of boxes and of questions within each box is flexible and adjusted to the narrative flow.

\section{Box A. Structure of the interview guideline}

A) Questions on the course of life after leaving school. This includes a narration on the time spent since leaving school until the current situation, plans for the future, the education and employment history, the migration history, and all topics relevant to the respondents' life-course.

B) Questions on the partnership history: This section collects information on the (present or former) partnership(s) and ideas on the future direction of their partnership. As to singles, we explore how they view their present situation and their experiences in former partnerships.

C) Questions on having children: We ask interviewees to provide us with information on their ideas, meanings, expectations, and experiences that they link or have linked to entering parenthood and starting a family. A special focus is on the process of decision making both on the individual and the couple level.

D) Questions on social relations: We explore how the respondent experiences her interactions with parents, friends, relatives, and peers regarding family formation, like talks or observations. We also ask for information on the perceptions of attitudes and actions of others concerning family formation.

E) This sections contains the structured survey of respondents' social networks (egocentered network), using a network chart and network grid. Additionally, the characteristics of the network partners and the relationships between this network and the interviewees are explored in depth (see the explanations in the next paragraph).

F) Questions on the perception of societal change: We ask the respondents to provide us with his or her views on the situation in Germany in general, on the 1990's (the time after unification for the respondents in East Germany) and on the local residential area or city concerning childcare supply and general attitudes on children and family.

G) Finally, questions on general values and aims in life: To sum up, we ask the respondents to tell us about their basic life orientations (such as religion, beliefs, values, life goals, etc.).

\subsubsection{The standardized tools: network chart, descriptors, and network grid}

The identification of the network relevant for a specific behavior is a central problem in research on social networks. The network-generator stimulus, generally a question - or a set of questions - affects the definition of the network and the consequent inferences that can be made on social influence (Hollstein 2003). In an effort to both assess and evaluate social 
networks of influence on fertility choices, we use an adapted version of the hierarchical mapping procedure that has been successfully employed in social psychology (Kahn and Antonucci 1980, Antonucci 1986). The original technique consists of asking respondents to use a diagram of graded concentric circles, with a smaller circle in the center containing a word representing Ego (see Figure 3).

[Figure 3 about here]

Our network chart is a slightly modified version of Kahn and Antonucci (1980) consisting of seven concentric circles. Each of the circles represents different levels of the perceived relevance of the network partner to the interviewee ${ }^{9}$. Respondents are free to define what they regard as a 'relevant' relationship. This can be related to Ego's degree of identification with Alter, to their emotional closeness, to his or her helpfulness in specific matters, or even to his or her negative impact on Ego's life. We use this open stimulus as a first step to explore the variety of different dimensions of relevance and in order to asses what kind of relationships are relevant for fertility decision-making ${ }^{10}$.

In addition, we can explore whether these differences are systematically related to the respondent's characteristics or to the research setting (East or West Germany). While the respondents fill out the charts, we also ask them to explain in their own words the choices they are making, like the reason behind including a specific person and the meaning of placing that person in a given circle. Since previous studies show that emotional and material support have significant effects on fertility intentions and behavior (Hammer et al. 1982, Belsky and Rovine 1984, Kohler and Buehler 2001), we always ask the respondent to specify the way in which the person is relevant. The aim of this step is to identify the social networks defined at least along the two important dimensions of emotional closeness and social support $^{11}$. For each individual mentioned in the network, 'descriptors' are collected in order to

\footnotetext{
${ }^{9}$ In the center circle, the term "I" is given, the two next innermost circles are labeled "very important". The following two circles and the two outermost are labeled "important" and "a little bit important" respectively. Outside the circles there are two additional fields which are labeled "problematic" persons and persons who are "not important".

${ }^{10}$ The stimulus reads like this: "The circle in the center of the chart is you. In the circles around you, you can place the people you know: You can say at the same time how important they are to you at present. In the two innermost circles you can place persons that are very important to you, in the two middle circles persons that are important, but nor very important, and in the two outermost circles persons who have little importance to you. If there are people who are problematic at the moment or for whom you explicitly want to state that they are not important to you, please place them in the additional fields."

${ }^{11}$ We initially required interviewees to fill out two additional charts that were specifically formulated to capture the dimensions of emotional closeness and material support. Here we were varying the network generating stimulus to elicit social network configurations related to these dimensions. However, we had to abandon the idea since the interviewees were not responding positively to these shifts.
} 
have an essential demographic profile and a qualification of the relationship with ego. These descriptors are individual characteristics like their age, occupation, marital and union status, where they live, whether and if so, since when they have children, their attitudes on children and family, the duration of their ties with Ego, the frequency of their contacts, and in which occasions they meet or talk.

The chart method has some advantages and disadvantages. An advantage is the cognitive facilitation for the respondents when placing their network-partners into a graph. This improves clarity and the recalling of the network partners. Another advantage is the possibility of comparing the network characteristics (e.g. size, density, composition). The methodological drawback of the chart is that its reliability and validity are open to criticism. Here, the instructions provided at the beginning determine the course. The more specific the instruction is formulated, the greater is the reliability of the method, but the more the validity to the research topic becomes questionable - and vice versa, therefore particular caution is necessary when interpreting the measures. ${ }^{12}$ From the network chart we learn about the network size, its composition and the closeness between Ego and Alters. However, we are still missing the information about the relative density of the network and the strength of the ties between the Alters. This information is collected by means of a classic network grid.

The ten persons rated most highly in the chart are entered in a matrix grid. The respondents are asked to indicate the extent to which these persons are acquainted or befriended with each other (on a 0-4 scale). By means of the combined use of the chart and the grid, we can calculate Ego's and Alter's network characteristics as strength of ties and density. With chart and grid, we obtain five different quantitative indices for each network, its size, the average closeness, the average strength, the density, and the percentage of kin (the definition of these indexes can be found in Box B). The respondent's perceptions of his or her personal relationships collected in the unstructured part of the interview are read also in the light of the configuration of his or her social networks. While these numerical indices are only moderately reliable and valid for the individual case when comparing groups of respondents, the differences between their average ratings can be tested for statistical significance between population subgroups (East-West, women- men).

\footnotetext{
${ }^{12}$ In this study, we apply a compromise solution by providing open initial instructions which we extend in the following qualitative part by including two additional dimensions ("emotional close" and "practically supportive"). For details, see Hollstein (2001, 48ff.) and Bernardi, Keim and von der Lippe (forthcoming).
} 


\section{Box B. Description of social network indexes}

1. Network size: the number of network members as provided in the network chart.

2. Network density: the number of existing ties (alter knows alter) over the number of potential ties among the Alteri mentioned in the network grid, that is the most important ten.

3. Network closeness: the average rating of the Alters in the network chart (range 0-6)

4. Network strength: the average rating of the weight (or strength) of the relationships among Alteri in the grid (range 0-4).

\subsubsection{Interviews with Alters as dyads interviews}

As described in the sampling procedure, we aim at interviewing up to three network members in addition to Ego. We focus on individuals rated as the most important to Ego, generally one of the best friends, the partner, one of the parents, one of the siblings. We conduct the same interviews with peers (friends, partners, or siblings) as with Ego. As to interviews with Alters from the parent generation, we focus on the current relations with Ego and his or her family behavior and do not investigate the retrospective childbearing decision-process of Alter or her current social networks. With these dyad interviews, we move beyond the information on Alters provided by Ego and explore the perspective of Alters on our research questions and on Ego. The advantage here is the unique opportunity to compare different peers, and gender and generational perspectives on the same family formation process.

\section{Method of analysis ${ }^{13}$}

The research design outlined above is strictly related to our analytical approach. It aims at revealing the meanings associated with fertility decisions in different social contexts and the way in which the mechanisms of social influence on fertility decisions vary depending on the characteristics of social interaction. Qualitative and quantitative analysis are directed towards this research focus.

The comparative method is the dominant principle of the analytical process in qualitative research. As to our qualitative analysis, we proceed with a method suited to the group comparison of social representations, namely "thematic coding" (Flick 1999, 2002). This analytical approach to open interview data assumes that in different social groups there are

\footnotetext{
${ }^{13}$ Given that the collection and entering of data are far from complete only part of the procedure we expose in this section has been applied so far.
} 
different views on and understanding of processes, events, or social occasions. The processes we want to understand for our purposes are childbearing decision-making as to first and second birth and the effect of social interaction on this process. We have two levels of comparison of groups. On the one hand, we compare groups defined by different sociodemographic characteristics like East and West Germans, the higher and lower educated, men and women (our purposive sampling criteria). On the other hand, we compare dyadic relations, like pairs of friends, pairs of partners or couples, pairs of parents and children as a meaningful grouping typology for the processes of social influence. In both cases, we follow sequential steps in the analysis, which we will sketch here ${ }^{14}$ :

- The subdivision of the interview text in extracts of straightforward content interpretation; these constitute the thematic structure (TS) of the interview (for instance; all passages of respondents talking about their ideas on working part-time after the child has been born are coded as "prefers working part-time").

- The re-organization of the text extracts on a conceptual level in meaningful categories (for example, the code "prefers working part-time" is listed under the category "compatibility of family and work") and a summary of the interview's main contribution to the research questions.

- A comparison of categories between interviews in the same dyad and the summary (here, we look for similar expressions and ideas mentioned by Ego and Alter, for example if both of them support the male bread-winner model).

- A comparison of categories between interviews in the same subgroup and the summary

- A comparison between similar interviews across subgroups and the summary. This system of categories constitutes the specific TS of the subgroup, which can be compared with the system of other subgroups. From this comparison, the emergence of similarities and differences between the TS is the main ground to capture the various meanings associated with processes and events in various subgroups.

The quantitative part of the analysis focuses on the dyad and network information. Taken together, our interviews will have produced data on about 60 ego-centered networks of close ties, each of which potentially provides information on network structure and composition, like the percentage of family and peers, childless individuals and parents, men and women, employed and unemployed. Basic statistical techniques to test differences across groups constitute the first stage of the quantitative analysis. Further, we focus on the various network configurations and construct a coherent model of influence, which takes into account this

\footnotetext{
${ }^{14}$ The reader can refer to Boeije (2002) for a complete discussion of the rationale of this procedure
} 
element. In addition to network data, there are 120 peer dyads that contain information on the quality of the tie (like the strength of the tie, the multiple role of the relationship, homophily), the kind of conversation or observation on family formation events exchanged within each relationship, the kind of social influence mechanisms at work, if any. With appropriate standardized coding, this information could provide a unique dataset to test the theories on variations in social influence mechanisms according to tie characteristics. For example, we would be able to test gender specific domains of influence, like the fact that staying childless is more likely to be a topic of conversation for women than for men in their 30s.

The final step of the analysis is to compare the findings of the network and dyad analyses to the categories of meanings issued from the interview analyses. We are then able to investigate whether similar network structures and ties of comparable strength have different ways of conveying social influence if embedded in different group-specific 'cultures of reproduction'.

\section{First insights (from a limited data set)}

In the following, we present some first insights based on twelve dyad interviews of Egos and their best friends. Figure 4 shows the basic characteristics of these interviews.

[Figure 4 about here]

The best friend dyads are already available for the twelve ego-interviews, and allow a varied scope of different living arrangements, parities, and gender. They all belong to the same educational subgroup, that is, the higher educated sample. We analyzed them and used them as a basis for provisional reflections, with the purpose of illustrating the potential analysis to be performed with this dataset when the interviews are completed and available. In the first subsection, we demonstrate how a comparison of single interviews across groups provides interesting insights into the conceptualization of the fertility decision-making process as well as the role of social influence in this process. In the second and third subsection, we discuss the potential use of dyad interviews but the analysis is at too early a stage to draw conclusions. Similarly, in the last subsection we discuss the use of the network characteristics in a comparative perspective across groups and give an illustration comparing the East and West German sample of higher educated respondents. 


\subsection{Subjective meanings: stability and parenthood}

The role of stable employment and career perspectives emerges as one of the fundamental categories that differentiate East and West Germans when analyzing the intention of and the actual transition to parenthood. In the Lübeck context, parenthood is conceivable only in conjunction with stable or promising employment which is repeatedly indicated as "Grundlage ${ }^{15}$ for a family (L05 man childless). In the context of Rostock, parenthood is conceived and realized within a more flexible framework as far as employment conditions are concerned.

Among our relatively young adults in their late 20s, the degree to which children and the family as such are appreciated is generally high, both in the Lübeck and the Rostock subsample. The thematic categories related to the desire for children are comparable in their content. A life with children is mostly taken for granted, particularly by women. In parallel, men are relatively sure to join the family plans of their partners.

However, the categories associated with these general aspirations to parenthood, those referring to the conditions and the ideal situation for having children read very diverse. In the West, when and at which conditions family planning can be conceived is well summarized in the sequence of words that seem to be echoed across the interviews: "first education, then a job, then a first child". Most important for men, this sequencing applies to both men and women. In other words, the establishment of one of the two partners in the labor market is a general condition for changing from a latent desire for children to a concrete family-planning situation.

"It was always a question of when to have children. Yes, first [my partner] wanted to finish his studies, then he wanted to have a job. It was never a question whether or not to have children, only a question of when. And when he finished his studies and got a job, we said OK" (L17,female ego, one child)

"I want to finish my education first and then find a job. This would be all very important for me [concerning starting a family], that at least one partner can rely on a steady income" (L02, male ego, childless)

A stable job situation and the model of the male breadwinner as well as an alternation of staying at home and part-time employment for the woman are choices that seem natural to the interviewees in Lübeck and these respondents do not feel they have to give further justifications for their choice.

"In the ideal case [of family-formation], with a man at my side who then - well, somebody needs to work, doesn't he - who is working and I am at home and take care of

\footnotetext{
${ }^{15}$ basis
} 
the child. (...) Well, if I give birth to a child, I would really like to enjoy this time. I would like to stay at home then and be there for the child. (...) I imagine that I will stay at home as long as I want to and then can go back to work" (L04, female ego, childless)

In the "Eastern interviews", the thematic structure seems to associate family planning with secure jobs in a way much different to the western interviews, either because the two are simply not connected or because the sequencing is turned around. Giving birth appears to be a well-suited choice in times of professional uncertainty, job transition, or while waiting to continue studies. East German women evaluate improvisation of childbearing timing positively and order the sequencing of their life events in a flexible way. They sometimes express an almost ideological polemic position against the western pattern:

"For me, this attitude is very strange: that you need to have so many things prepared in order to have a child, that thousands of things are important conditions for a child. There is real stress for many people, all that you need to consider and justify before having a child-it almost seems impossible to just simple get one. (...) Well for me, when I waited to be accepted by the university, I told myself: Either I am accepted now or I get a child. And then I was very quickly pregnant. (...) My boyfriend was still doing his studies at this time but now he has graduated" (R16, female ego, one child)

"And this friend of mine is really in a 'dead end' in her job at the moment. The owner of her company is changing constantly, she never knows if her team will dissolve or not or if she will lose her job, so that's well possible that she allows herself a break from all this stress [by having a child]" (R11, female ego, one child)

This flexible attitude can't be interpreted as a consequence of a negative or loose attitude towards job-related achievement. For none of the Eastern respondents, flexibility means that any of the partners loses his or her work orientation or gives up employment. Having "some kind of job" is clearly connected for both men and women with parenthood, but how this job should precisely look like and how stable it is no the main point. This relatively vague definition contrasts with the very clear-minded opinion expressed in the narratives of the western interviewees.

These insights need further analysis at the level of language used to indicate planning, and stability in the different contexts. However, the difference in the theoretical category of compatibility already shed some light on the ongoing demographic debate on the reasons for the persisting differences in East and West German fertility patterns. As we mentioned in Section 3.1., one persisting difference between East and West German fertility is that in the East, first children still are born earlier than in the West, and even earlier if the mothers are unemployed (Kreyenfeld 2004). How do we interpret these findings? The author has offered two speculative arguments. One possibility is that unemployed females are selected women who, having small chances to get a job, lean towards a pro-family choice earlier than do others. The second possibility, which is equally likely, is that East German women have 
recently developed a preference for the home-keeper model. This model was socially unacceptable until unification and stood in contrast to the high work-orientations emanating from the moral and social pressure on women to be mothers and to be employed full-time at the same time exerted by the previous regime. When listening to the stories of the young East German mothers, potential and current ones, telling about themselves and their planned parenthood, and comparing the meaning attributed to them to stability and participation in the labor market, the second interpretation does not hold. The labor-force orientation of East German women and men is relatively stable but it is more flexible than in the West. Economic uncertainty may therefore have very different consequences on the postponement of childbearing in the two contexts.

\subsection{Best friends dyads}

In the previous section, we concentrated on the subjective meaning of stability and uncertainty as it emerged from the two groups of interviews, considering narratives relatively independent from each other. However, in order to appreciate how beliefs, meanings, and norms related to parenthood are traded and negotiated within informal personal communities (Mitchell 1974) and how social influence works we gain from confronting narratives of individuals who interact with each other. One way of investigating these social effects of communication and observations among individuals in social interaction is to look at social effects on behavior. This approach answers questions like: With all other things being equal, is it more likely that individual fertility intentions conform to the expectations and/or supporting availability of his or her social network? We provided examples of research following this kind of approach in Section 2.2. While this approach shows the presence of social effects, it does not investigate directly the social mechanisms at work.

We prefer a complementary approach, which is to examine pairs of individuals who declare to be in frequent and intense contacts. Here, the questions to answer are more of the kind: How are expectations as to family formation conveyed within the circles of informal relationships? How is the support negotiated? How do people talk about these issues and what kind of arguments and behavior are they sensitive to? Ideally, one would want to observe these interactions. In most cases, this is unfeasible and very time consuming, given the privacy of the setting and the causality with which they may occur. A compromise solution is to listen to the multiple voices that participate in these interactions one at a time. Talks and observations of parents, friends, colleagues, acquaintances, or other relatives are on topics such as the optimal age of childbearing, the division of tasks between the interviewee and the partner, decisions in favor of parenthood, family-formation, family planning, children in general and childcare in particular. 
We looked at our few available dyad interviews in this perspective. The 'products' of some of the exchanges mentioned above, whether they are mentioned by the interviewees themselves or reconstructed by means of our comparative strategy of best friends interviews, are listed below:

- Reinforcement and resistance. Childbearing desires and hopes to have a family (despite the demands of the labor market to the contrary or partnership disappointments) are kept alive in frequent conversations (R02ef0 and R02ff0; L10ef0 and L10ff0). A delay in family formation despite parental pressure in the opposite direction is reinforced as a result of friends' reciprocal support on the positive image of their status. (L16ef0 and L02em0).

- Mirroring and self reflection. The interaction between friends at very different stages of family formation or with very different family orientations intensifies the selfreflection on (current or future) family choices. Encouragement to have a child is received as expectations of future support both in terms of material help and moral support (R15em0 - R10em1; R03em0 - R16ef1; L08ef1 - L04ef0).

- Vicarious experience and social learning. Social interactions help to reflect on the interviewee's observations of births of second children in their circle of friends and to discuss this issue and reflect on their own personal situation (L06ef1 - L17ef1)

This stage of analysis is a very preliminary one. The next step will be a thorough examination of the arguments and the language used as well as the occasions in which interactions took place. Similarly to best friends, we will consider dyad interviews involving two partners living together and dyad interviews involving parent-child couples. These data are not yet available.

\subsection{Characterizing social networks and their variation}

The charts and grids instigate in-depth reflection on the respondents' web of relationships and influence mechanisms. They can also be used to extract standardized information to characterize informal networks and their possible variations between subgroups. The data are summarized in indexes, defined in Box B, Section 3.3.2., and are used to compare the sub-groups of the respondents. A comparison (by gender, residence, education) enables testing for statistical significance the differences between their average ratings. 
Below, we show one such comparison of the main network characteristics of the respondents from Rostock and Lübeck. Table 2 shows the results of the Welch test ${ }^{16}$.

Table 2: Network Characteristics

\begin{tabular}{|c|c|c|c|c|c|c|c|c|c|}
\hline \multicolumn{7}{|c|}{ Network characteristics } & \multicolumn{3}{|c|}{ Differences } \\
\hline & & $\mathbf{N}$ & Min & Max & Mean & SD & t-test & $\mathrm{df}$ & Sign \\
\hline \multirow{4}{*}{ 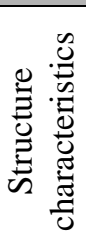 } & Size Rostock & 19 & 4 & 27 & 14,68 & 4,989 & \multirow{2}{*}{4,229} & \multirow{2}{*}{42} & \multirow{2}{*}{$* * *$} \\
\hline & Size Lübeck & 28 & 11 & 48 & 23,75 & 9,590 & & & \\
\hline & Density Rostock & 19 & 0,07 & 0,83 & 0,45 & 0,176 & \multirow{2}{*}{1,597} & \multirow{2}{*}{41} & \multirow{2}{*}{$*$} \\
\hline & Density Lübeck & 27 & 0,16 & 0,84 & 0,53 & 0,193 & & & \\
\hline \multirow{4}{*}{ 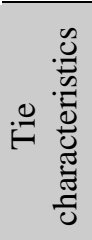 } & Closeness Rostock & 19 & 1,38 & 5,20 & 3,75 & 1,008 & \multirow{2}{*}{0,616} & \multirow{2}{*}{30} & \multirow{2}{*}{ Ns } \\
\hline & Closeness Lübeck & 28 & 2,48 & 5,00 & 3,58 & 0,729 & & & \\
\hline & Net strength Rostock & 19 & 0,71 & 2,50 & 1,58 & 0,482 & \multirow{2}{*}{0,968} & \multirow{2}{*}{42} & \multirow{2}{*}{ Ns } \\
\hline & Net strength Lübeck & 25 & 0,60 & 3,02 & 1,73 & 0,605 & & & \\
\hline
\end{tabular}

$* * *=1 \% ; * *=5 \% ; *=10 \%$

There seems to be little difference on average in the strength of and closeness in the relationships in the two contexts, although the more general structural characteristics seem to vary substantially, with Lübeck ego-networks being denser and larger. Size differences need to be read with caution however, since we cannot rule out interviewer effects having been exerted in the initial phase of the research project. In Lübeck, the interviewer carried out relatively intense probing in order to generate a larger number of names, whereas the Rostock interviewees were initially not probed as strongly. A homogeneous procedure has been developed after about a third of interviews had been performed.

The difference in density may be the result of large out-migration from East Germany after the Wende, which interested about one million people only in the two years between 1989 and 1991. The extent of the migration movement varies as to urban and rural settlements, the latter having lost proportionally more of its population than the former. However, between 1993 and 2002, even the city of Rostock recorded a decrease in its population of up to $20 \%$, from about 230.000 inhabitants to 200.000 , that is, within a ten year-time interval (Voigt 2004, p. 115 and 120). Particularly the younger cohorts who stayed in the city experienced a "forced" drain of friends and acquaintances, something that our interviewees constantly mentioned $^{17}$. For many of them, the physical distance translated into relational distance.

\footnotetext{
${ }^{16}$ We used a Welch test for independent sampling (Welch 1947) because of its robustness to unequal variances in the two samples.

${ }^{17}$ Many of the Egos and their friends who obtained their Abitur in 1994 are no longer living in Rostock or spend considerable time elsewhere before returning.
} 
At the end of the study, taken together, our interviews will have produced data on 64 egocentered networks of close ties, each of which provides information on network composition. We envisage to investigate also these compositional aspects of the networks in terms of sociodemographic characteristics, like age, union, gender and parity, and in terms of the kind of relationship involved, like the percentage of kin versus that of friends and so forth. In addition to network data, there will be 120 peer dyads that contain information on the quality of the ties (like its strength and multiple role, homophily), the kind of conversation or observation on family formation events exchanged within each relationship, and the kind of social influence mechanisms. We expect that matching the information on the thematic structure of single and dyad interviews concerning the influential mechanisms and the network configurations will allow us to construct a coherent model of social influence on fertility decision-making.

\subsection{Conclusions}

In this paper, we have introduced a research design for studying social influence on fertility. The innovative aspect of the study is its flexible data collection tool consisting of in-depth interviewing, network charts and grids, all of which allows for the contextual collection of very rich information on the social influence exerted on individual fertility decision-making from multiple perspectives We gain these multiple perspectives from the analysis of the single dyads of relationships (partners, parent children, best friends) as well as from the comparison of different contexts (gender, education, or family culture). The study is still under way; therefore there are no empirical insights yet to summarize or discuss unless they are taken as illustration that the analysis to follow has. We recall the three main focuses of the analysis. First, the vocabulary of attitudes, expectations, and preferences on fertility and parenthood which defines the meanings associated with parenthood and the conditions for it as well as the relation between these meanings.

Second, we focus on the exploration of the reported perception of social mechanisms from multiple points of view. The voice of our respondents is collected from the multiple voices of ego and relevant others within the network. A content analysis of these related narrative interviews reveals the presence of social influence on the construction of meanings related to fertility.

Third, a methodological approach that contextually collects and analyzes narrative in-depth interviews and comparable measures of network characteristics breaks with the artificial distinctions between qualitative and quantitative approaches. We expect that the triangulation implicit in these multiple perspectives will be a source of reflection on the different methodologies used and on the advantages and disadvantages of each of them. 


\section{Acknowledgments}

The authors would like to thank Susann Backer for editing the English of this draft and Tina Hannemann for helping with the data management. 


\section{References list}

Antonucci, T. (1986). Hierarchical Mapping Technique. Generations, (Summer), 10-12.

Amato, P. R. (1991). Parental absence during childhood and depression in later life.

Sociological Quarterly, 32(4), 543-556.

Behrman, Jere R., Kohler, H.-P., Cotts Watkins, Susan. (2002): Social Networks and Changes in Contraceptive Use over Time: Evidence from Longitudinal Study in Rural Kenya.

Belsky, J./ Rovine, M. (1984): Social network contact, family support and the transition to parenthood. In: Journal of marriage and the family, 46, S. 455-463.

Bernardi (2002), Personal relationships and reproductive choices: evidence from a low fertility context, Ph.D. Dissertation, Universita' di Roma, la Sapienza.

Bernardi, L. (2004). Channels of Social Influence on Reproduction . Population Research and Policy Review , 22(5-6), 527-555.

Bernardi, L./ Keim, S./ von der Lippe, H. (forthcoming). Freunde, Familie und das eigene Leben. Zum Einfluss sozialer Netzwerke auf die Lebens- und Familienplanung junger Erwachsener in Lübeck und Rostock. In: Hollstein, B. and F. Straus (Ed.): Qualitative Netzwerkanalyse. Konzepte, Methoden, Anwendungen. Wiesbaden: VS Verlag für Sozialwissenschaften.

Bocquet-Appel/ Jean-Pierre/ Jakobi, Lucienne (1998). Evidence for a Spatial Diffusion of Contraception at the Onset of the Fertility Transition in Victorian Britain. Population. An English Selection 10 (1), S. 181-204.

Boeije 2002, A purposeful Approach to the constant Comparative method in the Ananlysis of Qualitative Interviews, Quality and Quantity 36: 391-409, 2002

Bongaarts, John/ Watkins, Susan (1996). Social Interactions and Contemporary Fertility Transitions. Population and Development Review 22 (4), S. 639-82.

Bühler (2004), The expectation that children will raise their parents's social capital and its impact on fertility intentions: first results from Bulgaria. Poster presented at the Annual Meeting of the Population Association of America Boston, MA (United States), April 2004,

Bühler, Christoph/ Fratczak, Ewa (2004): Social Capital and Fertility Intentions: The Case of Poland. MPIDR Working Paper WP 2004 - 012.

Busfield, Joan/ Paddon, Michael (1977): Thinking about Children. Sociology and Fertility in Post-War England. Cambridge: Cambridge University Press.

Campbell, E. (1985). The Childless Marriage London: Tavistock Publications.

Chattoe, E. (2003): The Role of Agent Based Modeling in Demographic Explanation, in Billari F. and A. Prskawetz, Agent Based Computational Demography, Physica Verlag.

Cleland, John/ Wilson, Christopher (1987): Demand Theories of the Fertility Transition: An Iconoclastic View. Population Studies 41(1), S. 5-30.

Flick, Uwe (1998): Qualitative Forschung. Theorie, Methoden, Anwendung in Psychologie und Sozialwissenschaften. Reinbek: Rowohlt.

Flick, Uwe (2002): An introduction to qualitative research. London: Sage.

Flick, Uwe/ von Kardorff, Ernst/ Steinke Ines (Hrsg.) (2000): Qualitative Forschung. Ein Handbuch. Hamburg: rowohlts enzyklopädie.

Freedman R/ Takeshita J.Y. (1969). Family Planning in Taiwan: An Experiment in Social Change. Princeton, NJ: Princeton Univ. Press 
Gerson, Katheen (1985): Hard Choices - How Women decide about work, career, and motherhood. Los Angelos, California. University of California Press.

Glaser, Barney G./ Strauss, A. L. (1998 (engl. 1967)): Grounded Theory. Strategien qualitativer Forschung. Bern, Göttingen, Toronto, Seattle: Hans Huber.

Hammer, Muriel/ Gutwirth, L./ Phillips, S. L. (1982): Parenthood and social networks: a preliminary review. In: Social science \& medicine 16, S.2091-2100.

Hollstein, Betina (2001): Grenzen sozialer Integration. Zur Konzeption informeller sozialer Beziehungen und Netzwerke. Opladen: Leske \& Budrich.

Hülser, O. (1996): Frauenerwerbstätigkeit im Transformationsprozeß der deutschen Vereinigung, Beiträge zur Arbeitsmarkt und Berufsforschung 194, Nuremberg.

Kahn, Robert L./ Antonucci, Toni C. (1980): Convoys over the life course : attachment, roles and social support. In: Life-span development and behavior; 3: 253-286.

Keim, Sylvia (2003): „So richtig deutsch wird man nie sein...“ Junge Migrantinnen und Migranten in Deutschland. Zwischen Integration und Ausgrenzung. Frankfurt a. M.: IKOVerlag.

Knodel, John/ van de Walle, Etiennne (1979): Lessons from the past: policy implications of historical fertility studies 5(2), S. 217-45.

Knodel, John/ Havanon, Napapom/ Pramualratana, Anthony (1984): Fertility transition in Thailand: a qualitative analysis 10 (2), S. 297-328.

Kohler, H.-P. (2000), Social interaction and fluctuations in birth rates, Population Studies 54, 223-237.

Kohler, Hans-Peter/ Bühler, Christoph (2001): Social networks and fertility. In: Smelser, N.J.; Baltes, P.B. (Eds.): International encyclopedia of the social \& behavioral sciences. Oxford: Pergamon/Elsevier Sciences, 14380-14388.

Kohler, H.-P., Billari, F., \& Ortega, J.A. (2002). Towards a Theory of Lowest-Low Fertility, Population and Development Review, Vol. 28 (4), S. 641-680.

Kreyenfeld, Michaela (2001): Employment and fertility: East Germany in the 1990s. Dissertation. Rostock: University.

Kreyenfeld, Michaela (2004). Fertility Decisions in the FRG and GDR: An Analysis with Data from the German Fertility and Family Survey, Demographic Research, S3:11, 276-318.

Leslie, L.A., \& Grady, K. (1985). Changes in Mothers' Social Networks and Social Support following Divorce. Journal of Marriage and the Family, 47(3), 663-673.

Lin, N. (1999). Building a Network Theory of Social Capital. Connections, 22(1), 28-51.

Manski, Charles F. (2000): Economic Analysis of Social Interactions. The Journal of Economic Perspectives 14(3), S. 115-36.

McAllister, Fiona/ Clarke Lynda (1998): Choosing childlessness. London: Family Policy Studies Centre.

McNicoll, Geoffrey (1992): The agenda of population studies: a commentary and a complaint 18 (3), S. 399-420.

Mey, G. (1999): Adoleszenz, Identität, Erzählung. Theoretische, methodologische und empirische Erkundungen. Berlin: Köster.

Milardo, R. (1992). Comparative methods for delineating social networks. Journal of social and personal relationships, 9(3), 447-461.

Mitchell, J.C. (1974). Social Networks. Annual Review of Anthropology, 3 2 , 279-299. 
Montgomery, Mark R./ Casterline, John B. (1993): The diffusion of fertility control in Taiwan: evidence from pooled cross-section time-series models 47 (3), S. 457-79.

Montgomery, Mark R./ Casterline, John B. (1996): Social Learning, Social Influence and New Models of Fertility 22 (Supplement: fertility in the United States: new patterns, new theories), S. 151-75.

Nazio, T., \& Blossfeld, H.-P. (2002). The Diffusion of Cohabitation Among Young Women in West Germany, East Germany and Italy. Working Paper No. 62002 Globalife research group University of Bielefeld, 1-14.

Palloni, Alberto (1998): Theories and models of diffusion in sociology. CDE Working Paper No. 98-11.

Pollak, Robert/ Watkins, Susan C. (1993) Cultural and economic approaches to fertility: proper marriage or misalliance? In Population and Development Review 19 (3), S. 467-96.

Retherford, Robert/ Palmore, James (1983): Diffusion processes affecting fertility regulation. In Determinants of fertility in developing countries . Edited by R. Bulatao and R. Lee, New York: Academic Press.

Rogers, Everett M./ Kincaid, D. L. (1981): Communication networks: toward a new paradigm for research. New York : Free Press.

Rosero-Bixby, L., \& Casterline, J. (1993). Modeling diffusion effects in fertility transition. Population Studies, 47(1), 147-167.

Rosina and Di Giulio (2003): Diffusion of Cohabitations in Italy: a Link between Generations? Oral communication at the EAPS Conference Warsaw, 26-30 August 2003, Session Q1.

Strang, David/ Soule, Sarah (1998): Diffusion in organisations and social movements: from hybrid corn to poison pills. In Annual Review of Sociology 24, S. 265-90.

Tietjen, A.M. (1985). The Social Networks and Social Support of Married and Single Mothers in Sweden. Journal of MArriage and the Family, 47(2), 489-496.

Voigt 2004, „Bevölkerung von Rostock im 20. Jahrundert“ in Werz and Nuthmann, Abwenderung und Migration in Mecklenburg und Vorpommern, Vs Verlag: 113-122

von der Lippe, Holger (2004). Transitions to fatherhood in East Germany in the 1990s. Psychological determinants of childbearing and the meaning of entering into parenthood for young adults from Rostock: An event-history and qualitative composite investigation within the Rostock Longitudinal Survey. Magdeburg: Online Dissertation.

Watkins C. Susan (1987): The fertility transition: Europe and the third world compared . Sociological Forum 2(4) S. 645-73.

Welch, B. L. (1947). The generalization of students problem when several different population variances are involved. Biometrika, 34: 28-35.

Witzel, Andreas (1985): Das problemzentrierte Interview. In: Gerd Jüttemann [Ed.]: Qualitative Forschung in der Psychologie. Grundfragen, Verfahrensweisen, Anwendungsfelder., Weinheim: Beltz, pp. 227-255.

Witzel, Andreas (2000): The problem-centered interview. Forum: Qualitative Social Research, 1(1), (available at www.qualitative-research.net/fqs). 
Tables and figures

Figure 1: Sample design

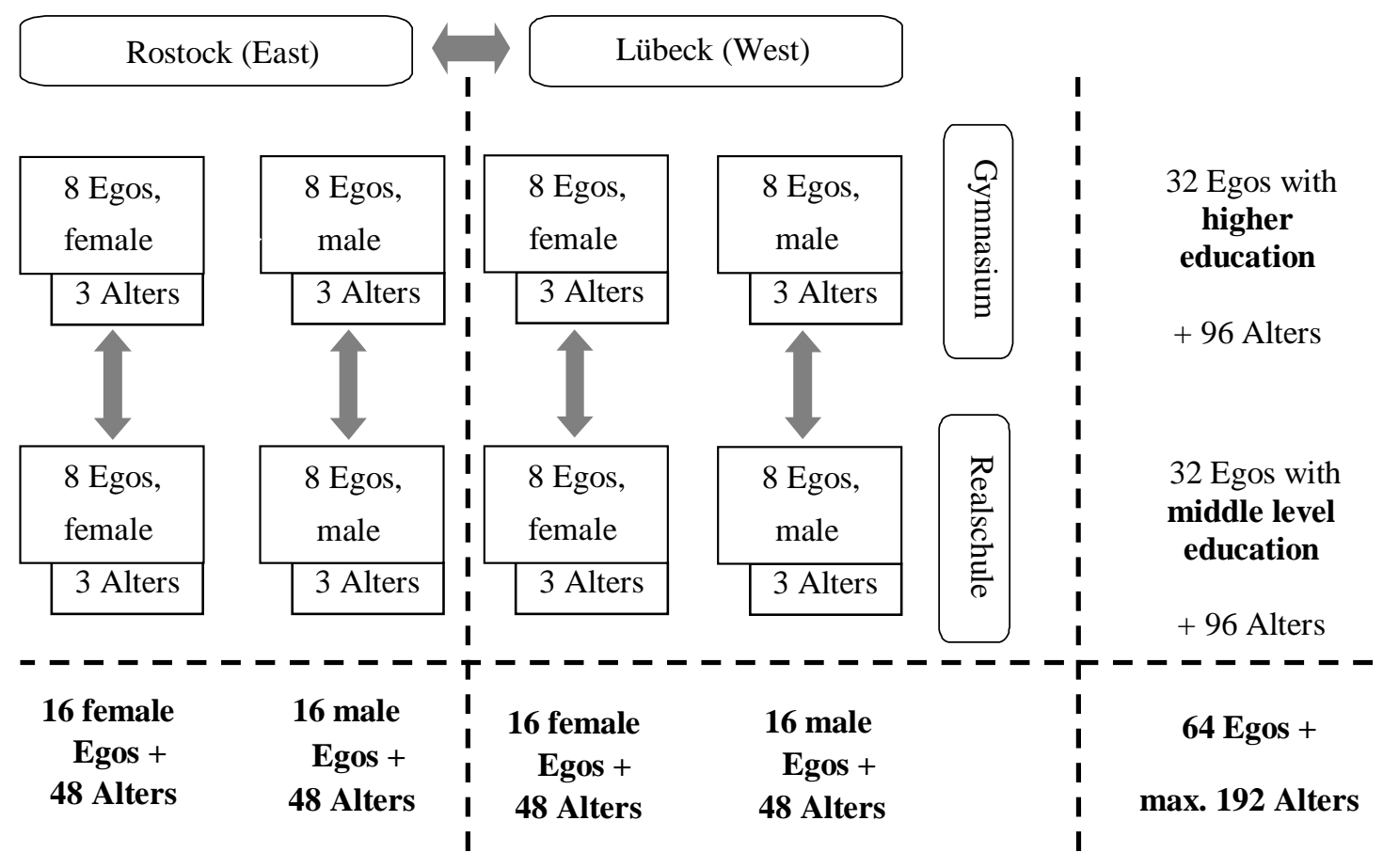

Table 1: Interviews collected until March 2005

\begin{tabular}{|c|c|c|c|c|}
\hline & \multicolumn{2}{|c|}{ Rostock (East) } & \multicolumn{2}{|c|}{ Lübeck (West) } \\
\hline \multirow{2}{*}{ 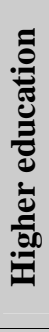 } & 11 female Egos & 7 male Egos & 12 female Egos & 6 male Egos \\
\hline & $\begin{array}{l}2 \text { single, parity } 0 \\
2 \text { LAT, par. } 0 \\
4 \text { cohabiting, par. } 0 \\
3 \text { cohabiting, par. } 1\end{array}$ & $\begin{array}{l}1 \text { single, parity } 0 \\
3 \text { cohabiting, par. } 0 \\
1 \text { cohabiting, par. } 1 \\
1 \text { married, par. } 1 \\
1 \text { married, par. } 2\end{array}$ & $\begin{array}{l}2 \text { singles, parity } 0 \\
3 \text { LAT, par. } 0 \\
2 \text { cohabiting, par. } 0 \\
1 \text { cohabiting, par. } 1 \\
4 \text { married, parity } 1\end{array}$ & $\begin{array}{l}3 \text { singles, parity } 0 \\
1 \text { LAT, par. } 0 \\
2 \text { married, par. } 0\end{array}$ \\
\hline & +17 Alters & +13 Alters & +21 Alters & + 10 Alters \\
\hline 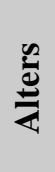 & \multicolumn{2}{|c|}{$\begin{array}{l}2 \text { partners } \\
21 \text { friends } \\
7 \text { parents }\end{array}$} & \multicolumn{2}{|c|}{$\begin{array}{l}6 \text { partners } \\
17 \text { friends } \\
4 \text { mothers } \\
4 \text { others }\end{array}$} \\
\hline & \multicolumn{2}{|c|}{18 Egos +30 Alters } & \multicolumn{2}{|c|}{18 Egos +31 Alters } \\
\hline
\end{tabular}


Figure 3: The Networkchart

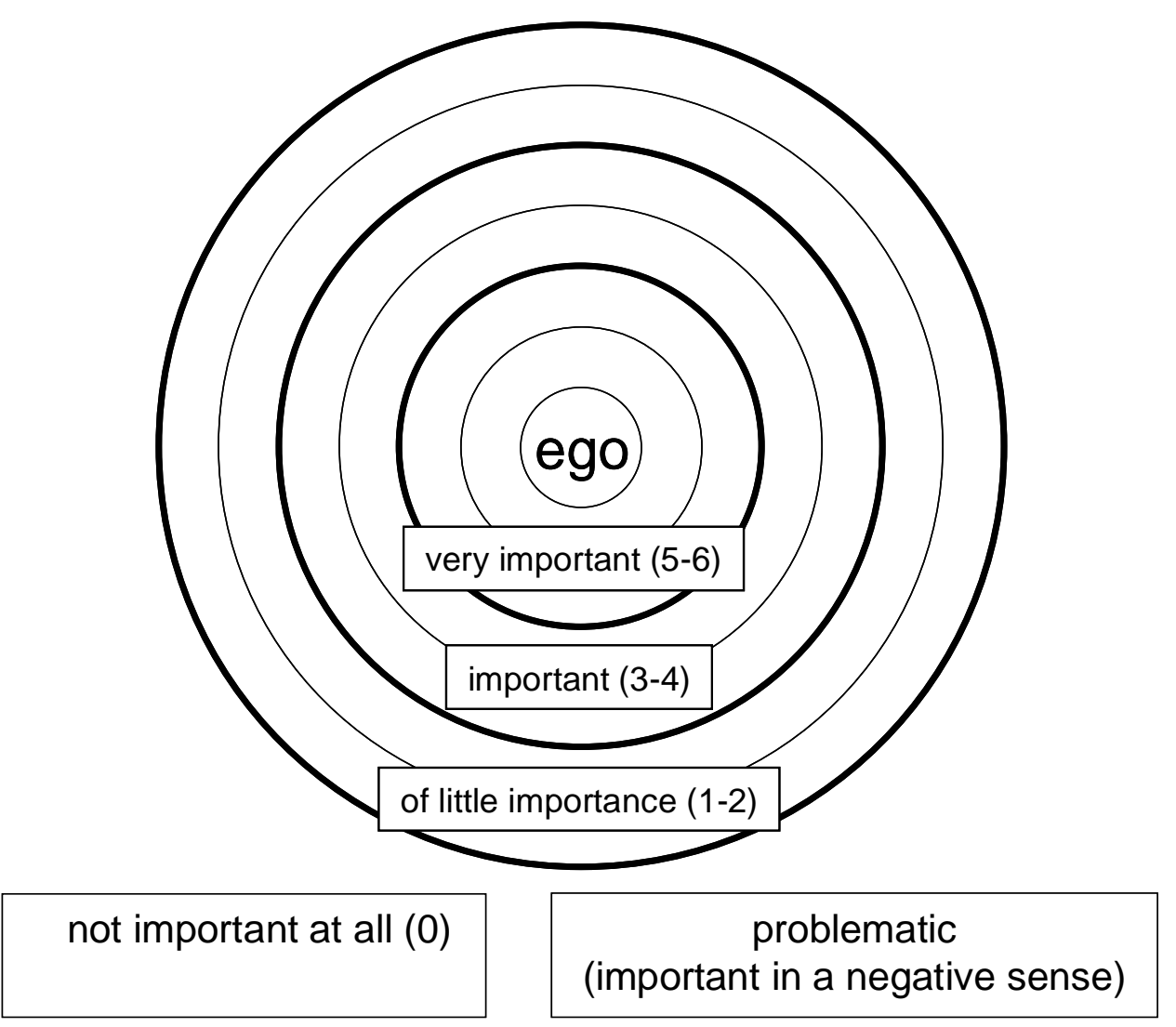




\section{Figure 4: Basic characteristics of best friend dyads}

\begin{tabular}{|c|c|c|c|}
\hline \multicolumn{4}{|c|}{ Egos with higher education } \\
\hline \multicolumn{2}{|c|}{ Rostock (East) } & \multicolumn{2}{|c|}{ Lübeck (West) } \\
\hline Ego & Alter & Ego & Alter \\
\hline $\begin{array}{l}\text { R15, } \\
\text { single man, par. } 0\end{array}$ & $\begin{array}{l}\text { R10, } \\
\text { cohabiting man, par. } 1\end{array}$ & $\begin{array}{l}\text { L10e, } \\
\text { single woman, par. } 0\end{array}$ & $\begin{array}{l}\text { L10f, } \\
\text { single woman, par. } 0\end{array}$ \\
\hline $\begin{array}{l}\text { R02e, } \\
\text { single woman, par. } 0\end{array}$ & $\begin{array}{l}\text { R02f, } \\
\text { woman (LAT), par. } 0\end{array}$ & $\begin{array}{l}\text { L02, } \\
\text { single man, par. } 0\end{array}$ & $\begin{array}{l}\text { L05, } \\
\text { single man, par. } 0\end{array}$ \\
\hline $\begin{array}{l}\text { R03, } \\
\text { cohabiting woman, par } 0\end{array}$ & $\begin{array}{l}\text { R16, } \\
\text { married woman, par. } 1\end{array}$ & $\begin{array}{l}\text { L16, } \\
\text { Woman (LAT), par. } 0\end{array}$ & $\begin{array}{l}\text { L02, } \\
\text { single man, par. } 0\end{array}$ \\
\hline $\begin{array}{l}\text { R11, } \\
\text { cohabiting woman, par } 1\end{array}$ & Not yet interviewed & $\begin{array}{l}\text { L08, } \\
\text { married woman, par. } 1\end{array}$ & $\begin{array}{l}\text { L04, } \\
\text { single woman, par. } 0\end{array}$ \\
\hline $\begin{array}{l}\text { R10, } \\
\text { cohabiting man, par. } 1\end{array}$ & $\begin{array}{l}\text { R15, } \\
\text { single man, par. } 0\end{array}$ & $\begin{array}{l}\text { L17, } \\
\text { married woman, par. } 1\end{array}$ & $\begin{array}{l}\text { L10, } \\
\text { single woman, par. } 0\end{array}$ \\
\hline $\begin{array}{l}\text { R07e, } \\
\text { married man, par. } 2\end{array}$ & $\begin{array}{l}\text { R07f, } \\
\text { single man, par. } 0\end{array}$ & $\begin{array}{l}\text { L06, } \\
\text { married woman, par. } 1\end{array}$ & $\begin{array}{l}\text { L17, } \\
\text { married woman, par. } 1\end{array}$ \\
\hline
\end{tabular}

LAT $=$ living apart together

The data collection is still under way and the data analysis proceeds in parallel, as it is most often the case for qualitative analysis. In this paper we will present insights only from 18 respondents belonging to the higher educational class (ABI) in both cities. These 18 respondents constitute 12 dyads of Ego and Alter friendship relations (some Egos are also Alters, marked in red). The schema below illustrates how these cases are subdivided by residence, union status, gender and parity. 